\title{
Correspondence
}

\section{Re: Treating Asthma and Comorbid Allergic Rhinitis in Pregnancy}

To the Editor: I have read with great interest the article by Yawn et $\mathrm{al}^{1}$ entitled "Treating Asthma and Comorbid Allergic Rhinitis in Pregnancy" in the May issue of the Fournal of the American Board of Family Medicine. They emphasized that nasal corticosteroids (budesonide), oral and nasal decongestants, and saline and oral or nasal antihistamines can be use for treatment of allergic rhinitis (AR) during pregnancy. However, no medications for the management of asthma or AR have been rated Pregnancy Category A; some drugs used to treat asthma or AR are rated Pregnancy Category B (such as budesonide). ${ }^{1}$

In their article ${ }^{1}$ they did not emphasize the role of cellulose powder extract spray (Nasaleze spray, Kisska International Ltd, Keighley, West Yorkshire, United Kingdom) in AR treatment. Limited data exist about Nasaleze nasal spray and $\mathrm{AR},{ }^{2-5}$ but this is a pure and safe plant-based extract that causes no known side effects. ${ }^{2-5}$ This spray can be use in pregnant and breastfeeding women, children, and adults with AR. It may be used more commonly in the future once successful clinical studies have been performed.

\section{References}

1. Yawn B, Knudtson M. Treating asthma and comorbid allergic rhinitis in pregnancy. J Am Board Fam Med 2007;20: 289-98.

2. Emberlin JC, Lewis RA. A double blind, placebo-controlled cross over trial of cellulose powder by nasal provocation with Der p1 and Der f1. Curr Med Res Opin 2007;23:242331.

3. Emberlin JC, Lewis RA. A double blind, placebo controlled trial of inert cellulose powder for the relief of symptoms of hay fever in adults. Curr Med Res Opin 2006;22:275-85.

4. Josling P, Steadman S. Use of cellulose powder for the treatment of seasonal allergic rhinitis. Adv Ther 2003;20: 213-9.

5. Teshima D, Yamauchi A, Makino K, et al. Nasal glucagon delivery using microcrystalline cellulose in healthy volunteers. Int J Pharm 2002;233:61-6.

Murat Enoz, MD

Department of Otolaryngology and Head and Neck Surgery

Maresal Cakmak Military Hospital

Erzurum, Turkey

muratenoz@gmail.com

doi: $10.3122 / \mathrm{jabfm} .2008 .03 .070262$

The above letter was referred to the authors of the article in question, who offer the following reply.

\section{Response: Re: Treating Asthma and Comorbid Allergic Rhinitis in Pregnancy}

To the Editor: I appreciate the interest Enoz has expressed in our publication. We agree that none of the medications we discussed in our article have been listed as Pregnancy Category A. Indeed very few studies have been done in pregnant women for any medication and so we are often left using Pregnancy Category B or even Pregnancy Category $\mathrm{C}$ medications when the benefits seem to outweigh any potential risks.

In regard to the use of Nasaleze spray for the treatment of allergic rhinitis during pregnancy, I read your references with interest. The first 2 are by the same author reviewing information for Current Medical Respiratory Opinions. ${ }^{1,2}$ The studies were not done in pregnant women. The third reference is an opinion piece and review. ${ }^{3}$ The fourth reference study does not really seem to be related to treatment of allergic rhinitis but to delivery of nasal glucagon - a phase 1 study to determine whether it can be done in healthy volunteers. ${ }^{4}$ Although interesting, these studies do not provide sufficient information for Nasaleze to be listed as a Pregnancy Category A, B, or even C. In fact it was not clear that this product has been reviewed by the FDA as a drug because it is currently listed as a medical device. It can be exported into the United States according to the Nasaleze websites.

The mechanism of action of Nasaleze is unknown but may be due to the cellulose powder reacting with moisture within the airway to produce a protective barrier over the nasal mucosa, preventing binding of inhaled allergens with receptors. ${ }^{1-3,5}$ I could find no study that discussed its use in pregnant women. ${ }^{6}$

I look forward to further developments that provide additional options for the treatment of allergic rhinitis in pregnant women. However, I do think it is important to remember that being "natural" does not automatically mean "safe" because many potent compounds such as digitalis and Coumadin are also "natural." If the product is inert and has no adverse effects when sprayed into the nose, swallowed, or inhaled, then indeed it may be safe but further study seems warranted.

Barbara P. Yawn, MD, MSc

Department of Research, Olmsted Medical Center, Rochester, $\mathrm{MN}$ yawnx002@umn.edu

\section{References}

1. Emberlin JC, Lewis RA. A double blind, placebo-controlled cross over trial of cellulose powder by nasal provocation with Der p1 and Der f1. Curr Med Res Opin 2007;23(10): 2423-31.

2. Emberlin JC, Lewis RA. A double blind, placebo controlled 